\title{
Evaluation of Tactics for Managing Resistance of Venturia inaequalis to Sterol Demethylation Inhibitors
}

\author{
Wolfram Köller and W. F. Wilcox, Department of Plant Pathology, Cornell University, New York State Agricul- \\ tural Experiment Station, Geneva, NY 14456
}

\begin{abstract}
Köller, W., and Wilcox, W. F. 1999. Evaluation of tactics for managing resistance of Venturia inaequalis to sterol demethylation inhibitors. Plant Dis. 83:857-863.
\end{abstract}

\begin{abstract}
The impact on the selection and control of subpopulations of $V$. inaequalis resistant to the sterol demethylation inhibitor (DMI) fenarimol or to dodine were evaluated with respect to several tactics of apple scab control. Experiments were conducted in an experimental orchard with elevated levels of DMI and dodine resistance over a period of three consecutive seasons. The DMIresistant subpopulation was poorly (14\%) controlled at a fenarimol rate of $15 \mathrm{mg} / \mathrm{liter}$ (sprayed to run-off), whereas control was significantly improved (54\%) at twice that rate. Mancozeb mixed with the low rate of fenarimol also improved the control of DMI-resistant isolates, but the improvement was due to the indiscriminate control of both the DMI-sensitive and -resistant populations provided by mancozeb. The selection of fenarimol-resistant isolates resulting from poor control of the resistant subpopulation by the low rate of fenarimol was equivalent whether fenarimol was applied singly or in mixture with mancozeb. Consequently, the use of high DMI rates in mixture with a protective fungicide is expected to delay the build-up of resistant subpopulations by limiting their increase through two separate principles of control. For dodine in mixture with fenarimol, it was found that each mixing partner applied alone selected both fenarimol- and dodine-resistant isolates. This selection pattern was partly explained by the possibility that one of the multiple genes underlying fenarimol and dodine resistance confers resistance to both fungicides, in addition to the selection of double-resistant isolates. Regardless, a mixture of fenarimol with dodine each employed at a low rate controlled both the fenarimoland the dodine-resistant subpopulation at least as effectively as the individual components at twice their mixture rate, and an accelerated selection of double-resistant isolates was not detected. In commercial orchard trials, mixtures of DMIs with either a protective fungicide or with dodine provided equivalent control even when levels of DMI resistance, dodine resistance, or both were moderately elevated. With the exception of orchards with high levels of DMI or dodine resistance, dodine might be an alternative to protective fungicides as a mixing partner with DMIs.
\end{abstract}

Several fungicides introduced in the 1980s for the control of tree fruit diseases act as sterol demethylation inhibitors (DMIs; 9,18). Practical resistance to DMI fungicides of Venturia inaequalis (Cooke) G. Wint., the causal agent of apple scab, was first documented for an experimental orchard in Nova Scotia, Canada, after DMIs had been tested at the site for more than 10 years $(2,3,16)$. Subsequently, similar resistance to DMIs was identified in a commercial orchard in Michigan (16), and evidence for resistance was provided also for orchards in Europe (19). In anticipation of resistance development of $V$.

Corresponding author: W. Köller

E-mail:wk11@cornell.edu

This study was supported in part by the USDA (90-34103-539 and 94-37313-0678) and by the New York State Apple Research and Development Program.

Accepted for publication 1 June 1999.

Publication no. D-1999-0706-03R

(C) 1999 The American Phytopathological Society inaequalis to DMIs, their mixtures with protective fungicides such as mancozeb or captan were suggested as an anti-resistance strategy (25); such mixtures are now commonly used for the control of apple scab with DMI fungicides. Tank-mixing DMIs with protective fungicides also has been recommended to improve the control of fruit infections in a delayed-spray program developed for low-inoculum orchards and with baseline-sensitive populations of $V$. inaequalis (31). The merits of such mixtures in delaying and managing DMI resistance have never been evaluated under orchard conditions. Furthermore, the reliance on purely protective fungicides as components of anti-resistance strategies might not be sustainable, because several of the suitable representatives remain under toxicological scrutiny in various countries.

Dodine, introduced in the late 1950s as a fungicide for control of apple scab, might serve as an alternative to conventional protectants in mixtures with DMIs. In addition to providing strong protective activity against scab infections, dodine also can be active when applied in pre- and post- symptom modes by preventing production of conidia from established scab lesions $(1,30)$. However, dodine efficacy is often weak in typical after-infection applications (30). In contrast, DMIs are most active in an after-infection mode of application, whereas their protective and anti-sporulant activities are weak $(22,26,30)$. Thus, mixtures of DMIs and dodine might be expected to complement the strength and weakness of each individual component in controlling scab at the various stages of disease development.

The effectiveness of DMIs in mixture with dodine will be influenced by the sensitivity of a given $V$. inaequalis population to both of the components. The first cases of dodine resistance were noted in the late 1960s, after the fungicide had been used extensively for approximately 10 years in scab control programs (7), and resistance became widespread during the 1970s $(7,8,20,27,32)$. A quantitative test for measuring sensitivities of $V$. inaequalis isolates to dodine allowed us to quantify frequencies of dodine-resistant isolates in both baseline populations and populations from orchards with practical resistance to dodine (17). Monitoring of orchards in New York and Michigan revealed that dodine resistance levels (i) largely reflected the dodine use histories at particular sites; (ii) had declined below threshold values in orchards with previous records of dodine resistance after dodine use was suspended for several years; and (iii) could quickly exceed threshold values when dodine was used as a single fungicide at sites where resistance levels were elevated (17).

The development of DMI resistance within populations of $V$. inaequalis in North American apple orchards $(2,3,16)$ signals the need for the development and implementation of effective anti-resistance strategies incorporated into current scabcontrol programs. The particular nature of resistance development to DMI fungicides has been described variously as directional, quantitative, or polygenic selection $(9,11$ 13,15). In general, baseline populations of fungal pathogens, including $V$. inaequalis, exhibit a broad range of isolate sensitivities to DMIs $(3,9,11-16,28)$; practical resistance develops when selection causes the frequency of the least-sensitive baseline isolates to increase above a threshold value (16). In contrast to other fungicides such as benomyl $(12,13)$, however, the response of isolates resistant to DMIs remains dose 
dependent (16). Consequently, a theoretical anti-resistance strategy would be to avoid the use of low application rates in order to maximize the control of isolates that would fully resist low doses of a DMI fungicide and, thus, would be selected more rapidly. In this study, the influence of DMI rates and of tank-mixing a DMI with either mancozeb or dodine was evaluated with respect to resistance development and apple-scab control in both experimental and commercial orchard trials.

\section{MATERIALS AND METHODS}

Test orchards. Tests were conducted from 1992 to 1994 in an experimental apple orchard (cv. Cortland) in Geneva, New York. This orchard was planted in 1967 and had served as a site for fungicide efficacy testing until 1987. The first DMI fungicides were tested in 1971 and increasingly intense DMI testing continued until 1987. Dodine was tested extensively in this orchard during the 1970s. From 1988 to 1991, the orchard served as a test site for insecticide and acaricides. Apple scab was controlled with DMIs during the four seasons preceding the tests described here.

Tests were also conducted in six commercial orchards in 1996 in cooperation with participating growers. The orchards (cv. McIntosh) were chosen to represent a typical cross-section of DMI use histories (i.e., each had been treated with fenarimol, myclobutanil, or both, predominantly in mixture with either mancozeb or metiram, for at least parts of the previous seven seasons). DMI resistance was not suspected by any of the growers. Each test block was approximately 4 ha in size, and all orchards were located near the south shore of Lake Ontario, three each in the counties of Wayne and Orleans. The two groups of orchards were separated by approximately $150 \mathrm{~km}$.

Application and evaluation of fungicides. In the experimental orchard, fungicide treatments were arranged in a randomized complete block design with three replications. Individual treatment-blocks consisted of two to three trees, and the same trees were assigned to the same treatment each year. Spray solutions were applied dilute (approximately 2,800 liters/ha) with a handgun to the point of runoff. The spray program was designed to target the period from tight cluster through first cover as suggested by Wilcox et al. (31); however, the timings of individual applications were adjusted more closely to specific apple-scab infection periods, with the objective of providing sufficient disease incidence to facilitate the monitoring of isolate sensitivities within each treatment regime.

In 1992, primary infection periods determined as described previously (31) were recorded on 25 April; 1, 17, and 26 May; and 6 and 13 June. Fungicides were applied on 5 and 21 May and 3 June. In 1993, very light primary infection forced us to extend the experimentation period in order to obtain sufficient isolate numbers for population profiling. In this year, infection periods were recorded on 22 April; 6, 19, 23, and 31 May; 20 and 29 June; and 14 July; fungicides were applied on 6, 17, and 28 May; 22 June; and 13 July. In 1994, primary infection periods occurred on 28 April; 8, 17, and 25 May; and 14 June; fungicides were applied on 3 and 19 May and 3 and 10 June.

The objective of the experimental orchard trials was to determine the impact of different DMI use strategies on the control of $V$. inaequalis subpopulations either sensitive or resistant to DMIs. Therefore, the evaluation of treatment efficacies was focused on the disease incidence of terminal leaves as the parameter most indicative of disease progression over the primary scab season. In order to allow for lesion development in response to the final treatment, scab incidence (10 leaves each on 10 terminals per tree from the central part of each plot) was assessed 2 weeks after the last fungicide spray was applied. Diseased terminal leaves with actively sporulating lesions were sampled for isolate sensitivity tests at or close to the time disease incidences were evaluated. A total of 40 to 50 isolates from individual and well-dispersed leaves $(16,17)$ were tested for each treatment in each season. In order to minimize significant mixing of the different subpopulations over the course of the experiments, leaves were sampled from the inner parts of respective treatment blocks. The potential for mixing of populations was further reduced by the low-density nature of the orchard (9-m row and 5-m tree spacing).

Growers cooperating in the commercial orchard trials in 1996 were asked to apply a DMI mixed with an ethylenebisdithiocarbamate (EBDC) to half of the test orchard, and a DMI-dodine mixture to the other half on the same dates, using their own application equipment, spray practices, and timing regimes. All growers started their scab-control program during the first week of May, at approximately the tight-cluster stage of blossom bud development as recommended previously for a reduced DMI spray program (31).

Orchards 1 to 3 and 6 received four DMI mixture applications, while orchards 4 and 5 received three and five applications, respectively. The mixtures were applied at intervals ranging from 5 to 15 days, with a mean interval of 11 days. DMIs used were commercial formulations of fenarimol (Rubigan 1EC) applied at a rate of $82 \mathrm{~g} / \mathrm{ha}$ or of myclobutanil (Nova 40W) applied at a rate of $140 \mathrm{~g} / \mathrm{ha}$. EBDCs used as mixture components were mancozeb (Dithane $75 \mathrm{DF}$ ) or metiram (Polyram 80WP) applied at rates of approximately 2,500 g/ha. Dodine (Syllit 65W) used as the alternative mixture component was applied at a rate of $820 \mathrm{~g} / \mathrm{ha}$. The DMI programs were fol- lowed by cover sprays applied to the entire orchard, consisting of captan alone, or captan mixed with sulfur or thiophanatemethyl. Scab incidences were assessed on 10 arbitrarily chosen trees per treatment by examining cluster leaves ( 25 clusters per tree), fruit (50 fruit per tree), and terminal leaves (10 leaves per terminal, 10 terminals per tree) during 25 June to 29 July.

In order to test the levels of resistance of the respective $V$. inaequalis populations to both DMIs and dodine at the start of the season, growers were asked to leave several trees at the orchard corners unsprayed until the scab incidence reached a level suitable for sampling. Diseased cluster leaves were arbitrarily sampled from these trees on a single date for each orchard during 28 May through 11 July.

Sensitivity tests. Procedures employed for the isolation and propagation of monoconidial isolates of $V$. inaequalis and for testing their sensitivities to fungicides have been described in detail $(17,28)$. Briefly, conidia originating from distinct scab lesions were germinated on water agar amended with antibiotics, and single germinating conidia were transferred to potato dextrose agar (PDA). Fungicide sensitivities of mycelia developing from single conidia were determined by comparing the colony diameters of mycelia developing on PDA or on PDA amended with a fungicide.

Isolate sensitivities were expressed as relative growth $(\mathrm{RG})$ of mycelial colonies at discriminatory doses of the respective fungicides, which were $0.05 \mu \mathrm{g} \mathrm{m}{ }^{-1}$ for fenarimol, $0.1 \mu \mathrm{g} \mathrm{ml}^{-1}$ for myclobutanil, and $0.2 \mu \mathrm{g} \mathrm{ml}^{-1}$ for dodine $(14,16,17)$. RG was defined as mean colony diameter on PDA amended with the discriminatory dose per colony diameter on unamended PDA $\times 100$. Fenarimol (technical grade) was obtained from Dow Agrosciences (Indianapolis, IN); myclobutanil (technical grade) from Rohm and Haas (Philadelphia, PA), and dodine (analytical standard) was from Cyanamid (Princeton, NJ). Fungicides used in orchard trials were commercial formulations as specified.

Data analysis. Sensitivities of $V$. inaequalis isolates to DMIs and dodine were analyzed as described previously $(16,17)$. Categorical sensitivity data were compared according to the log linear model of SYSTAT (version 5.2; Systat, Inc., Evanston, IL), with numbers of isolates grouped into the categories sensitive (S) and resistant (R). Isolates with RG values $>80$ determined for fenarimol were classified DMIresistant (16), whereas isolates with RG values >90 determined for dodine were classified resistant to that fungicides (17).

Mean RG values were compared with the nonparametric Kolmogorov-Smirnov test of SYSTAT version 5.2. Comparisons of mean RG values were restricted to isolates classified as sensitive to fenarimol or dodine. The objective was to detect any potential impact of scab control on the 
selection of least-sensitive isolates classified as DMI- or dodine-sensitive according to the criteria described previously $(16,17)$.

Additive, synergistic, or antagonistic interactions between mixture components were analyzed by applying the formula $\mathrm{E}_{\mathrm{xp}}$ $=X+Y-X Y / 100$ described by Richter (24), with $E_{x p}$ as the percentage of control expected from additive effects of the two components when tested in mixture, and with $X$ and $Y$ as the percentages of control provided by each of the two components independently. Synergism is indicated if the percentage of control observed with the mixture $\left(\mathrm{O}_{\mathrm{bs}}\right)$ is higher than the expected additive effect; antagonism is indicated if the observed control is lower than expected.

\section{RESULTS}

Sensitivities of $V$. inaequalis isolates to fenarimol and dodine. The frequency of fenarimol-resistant isolates $(\mathrm{RG}>\mathrm{80})$ sampled from leaves of non-treated trees in 1992 was $7 \%$ and significantly higher $(P=$ $0.05)$ than the frequency of $1.7 \%$ determined for typical baseline populations (16); the frequency of dodine-resistant isolates ( $R G>90)$ was $7 \%$ and also significantly higher $(P=0.02)$ than the baseline value (17). By the third year of our tests, resistance levels determined for isolates sampled from non-treated trees were $14 \%$ for fenarimol and $8 \%$ for dodine. Neither increase was significant $(P=0.3$ and 0.9 , respectively); therefore, all sensitivity data for isolates sampled from nontreated trees over the three-year period

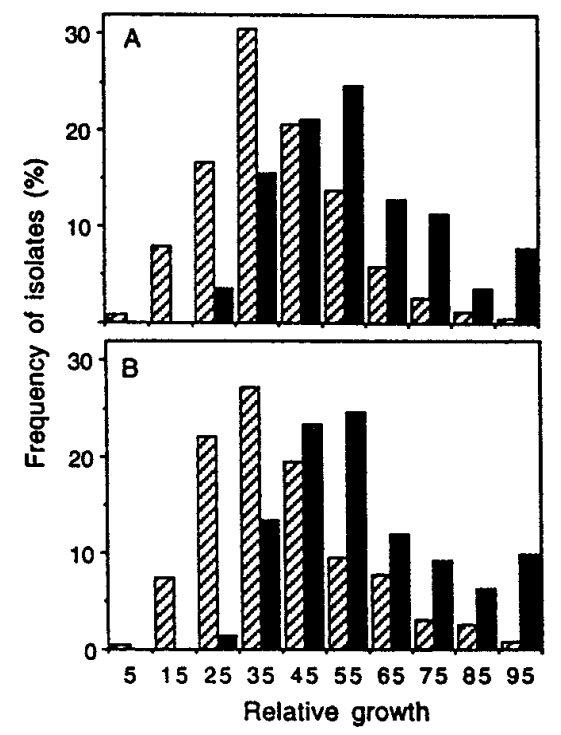

Fig. 1. Distribution of fenarimol and dodine sensitivities of Venturia inaequalis populations. (A) Fenarimol sensitivity distribution in baseline populations (hatched bars; $\mathrm{n}=748$ ) (16) and in the experimental test orchard (closed bars; $n=142$ ). (B) Dodine sensitivity distribution in baseline populations (hatched bars; $\mathrm{n}=$ 232) (17) and distribution in the experimental test orchard (closed bars; $n=142$ ). were combined to reflect the orchard population prior to treatments in individual plots. The sensitivity distributions of these isolates were significantly different from the distributions described for baseline populations (Fig. 1). In addition to significantly higher frequencies of resistant isolates, the mean RG value of the fenarimolsensitive subpopulation had increased from 41 in baseline populations (16) to $53(P<$ 0.01 ); the mean RG value of the dodinesensitive subpopulation was 55 compared to 41 in baseline populations $(P<0.01 ; 17)$.

Relative efficacy of apple-scab control. Fenarimol and mancozeb applied alone at half of the rates typically recomand $900 \mathrm{mg} /$ liter, respectively) provided the least control in all three seasons, whereas the combination of the two fungicides was significantly more effective (Table 1). The interactive effects of the two mixture components $\left(\mathrm{O}_{\mathrm{bs}}-\mathrm{E}_{\mathrm{xp}}=-5,+9\right.$, and +5 for 1992,1993 , and 1994, respectively) suggested that effects were largely additive. Fenarimol alone applied at twice the rate utilized in the mixture provided control equivalent to the half-rate mixture with mancozeb (Table 1). Although incidences of scab on non-treated trees ranged from 23.5 to $85.6 \%$ during the three years of testing, levels of control achieved with the various treatments were uniform, with the exceptions of fenarimol applied at the low rate and of dodine (Table 1).

The control of scab achieved with dodine at a rate of $290 \mathrm{mg} / \mathrm{liter}$, which reflects the low range of the rate typically recommended, was similar to the high rate were high (Table 1). The mixture of fenarimol and dodine was as effective as the single components applied at twice their mixture rates. Furthermore, the level of control achieved with this mixture was very consistent over the three years of testing (Table 1).

Impact of scab-control tactics on development of resistance to fenarimol and mended for commercial control of scab (15 of fenarimol, although seasonal variations

dodine. All treatments significantly increased the frequencies of fenarimol-resistant isolates relative to the population of isolates sampled from non-treated trees (Table 2). Differences among treatments in the frequencies of fenarimol-resistant isolates were not significant $(P>0.32)$. Mean RG values of fenarimol-sensitive isolates surviving the spray regimes increased significantly only for the low rate of fenarimol applied alone or in mixture with mancozeb (Table 2). Thus, isolates belonging to the least-sensitive part of the DMI-sensitive subpopulation (16) were selected by these treatments but not by the low rate of fenarimol mixed with dodine or the high rate of fenarimol applied singly.

All treatment regimes except the fenarimol-mancozeb mixture resulted in significantly higher frequencies of dodineresistant isolates (Table 2). The selection of dodine-resistant isolates was significantly more pronounced for the dodineonly treatment than for any other treatment $(P \leq 0.05)$, with the exception of fenarimol applied at the high rate $(P=0.14)$. A higher mean RG value for the dodine-sensitive population was detected only when dodine was applied as the single fungicide (Table 2), indicating that dodine at the rate it was used in our trials also selected isolates belonging to the least-sensitive spectrum of the population normally classified as dodine-sensitive (17).

Differential levels of control achieved for subpopulations sensitive or resistant to fenarimol or dodine. In order to evaluate the significance of differential levels of control achieved for either fungicide-resistant or -sensitive isolates (16), the incidences of apple scab recorded in each of the three years for non-treated trees and for trees subjected to the various treatments (Table 1) and the corresponding frequencies of fenarimol- and dodine-resistant isolates (Table 2) were utilized to separately calculate the percentages of scab control achieved for the sensitive and resistant subpopulations (Table 3).

Table 1. Control of apple scab with single fungicides and fungicide mixtures in experimental orchard trials

\begin{tabular}{lccccc}
\hline & & \multicolumn{3}{c}{ Incidence $^{\mathbf{w}}$} & \\
\cline { 3 - 5 } Treatment $^{\mathbf{x}}$ & Rate (mg a.i./liter) & $\mathbf{1 9 9 2}$ & $\mathbf{1 9 9 3}$ & $\mathbf{1 9 9 4}$ & Mean control (\%) \\
\hline None & $\ldots$ & 53.3 & 23.5 & 85.6 & $\ldots$ \\
Mancozeb & 900 & 29.0 & 12.9 & 35.6 & $50(7) \mathrm{a}^{\mathrm{z}}$ \\
Fenarimol & 15 & 15.3 & 14.4 & 44.5 & $53(17) \mathrm{a}$ \\
Fenarimol & 15 & 11.3 & 6.0 & 13.8 & $79(5) \mathrm{b}$ \\
+ Mancozeb & +900 & $\ldots$ & $\ldots$ & $\ldots$ & $\ldots$ \\
Fenarimol & 30 & 14.0 & 3.9 & 15.0 & $80(5) \mathrm{b}$ \\
Dodine & 290 & 11.3 & 1.8 & 31.0 & $78(14) \mathrm{ab}$ \\
Fenarimol & 15 & 6.7 & 4.1 & 13.1 & $85(2) \mathrm{b}$ \\
+ Dodine & +145 & $\ldots$ & $\ldots$ & $\ldots$ & $\ldots$ \\
\hline
\end{tabular}

${ }^{w}$ Mean percentage of terminal leaves infected.

${ }^{x}$ Mancozeb, fenarimol, and dodine were applied as Dithane 75DF, Rubigan 1EC, and Syllit 65 WP, respectively.

${ }^{y}$ Standard deviations are given in parentheses.

${ }^{z}$ Means not followed by a common letter are significantly different $(P \leq 0.05$, Duncan's multiple range test). 
Fenarimol applied alone at the low rate provided the least and least-uniform control of the fenarimol-resistant subpopulation (Table 3). Although control was $42 \%$ in 1992, no control was provided in 1993 and 1994. Applying fenarimol at twice the rate substantially $(P=0.07)$ improved control of the resistant population (Table 3 ). Differences were most pronounced for 1993 and 1994, during which mean control of the fenarimol-resistant subpopulation was $62 \%$ versus $0 \%$ for the high and low fenarimol rate, respectively.

Control of the resistant subpopulation was also substantially $(P=0.07)$ improved when fenarimol at the low rate was applied in mixture with mancozeb (Table 3). However, this improved level of control was due to the indiscriminate contribution provided by mancozeb. Eliminating this mancozeb contribution revealed that control of the fenarimol-resistant subpopulation provided by the low rate of fenarimol was equally poor $(P=0.87)$ whether the fungi- cide was applied alone or in mixture with mancozeb (Table 3). Likewise, the control of the sensitive population provided by the low rate of fenarimol contained in the mixture or applied alone was equivalent $(P=0.59)$, indicating that the relative contribution of mancozeb was additive for both the DMIresistant and -sensitive subpopulations. The most effective and most consistent control of the fenarimol-resistant subpopulation was achieved with the low-rate mixture of fenarimol and dodine (Table 3).

Because selection of dodine-resistant isolates was most pronounced for dodine applied singly (Table 2), poor control of the dodine-resistant subpopulation was also expected to be most pronounced for this treatment. The data reflected this expectation, but the differential control of the dodine-sensitive and -resistant subpopulations were of low statistical significance (Table 3) due to the variable control of the dodine-resistant population provided by dodine applied alone (percentages of con- trol were 43, 78, and 3 in 1992, 1993, and 1994, respectively). The best and most consistent control of the dodine-resistant subpopulation was achieved with the dodine plus fenarimol mixture (Table 3), very similar to the consistently high level of control of the fenarimol-resistant population provided by the same mixture.

Although differences were not always of high statistical significance due to the sometimes large variations over the three test seasons, control of the fenarimol-resistant subpopulation was consistently lower for all treatments, including dodine applied alone (Table 3). Conversely, the inferior control of the dodine-resistant population with fenarimol also was observed (Table 3 ).

Interdependence of DMI and dodine resistance. The possibility that the selection of fenarimol-resistant isolates by dodine and vice versa (Tables 2 and 3) might be explained by the selection of isolates double-resistant to both inhibitors

Table 2. Levels of resistance of Venturia inaequalis populations controlled with fenarimol, dodine or fungicide mixtures

\begin{tabular}{|c|c|c|c|c|c|c|c|}
\hline \multirow[b]{2}{*}{ Fungicide } & \multirow[b]{2}{*}{ Isolate values } & \multirow[b]{2}{*}{ Check $^{\mathbf{v}}$} & \multicolumn{5}{|c|}{ Treatments $^{\mathrm{u}}$} \\
\hline & & & Fenarimol (15) & Fenarimol (30) & $\begin{array}{c}\text { Fenarimol }(15)+ \\
\text { mancozeb }(900)\end{array}$ & Dodine (290) & $\begin{array}{c}\text { Fenarimol }(15)+ \\
\text { dodine }(145)\end{array}$ \\
\hline \multirow[t]{5}{*}{ Fenarimol } & $\mathrm{n}$ & 142 & 133 & 149 & 150 & 150 & 150 \\
\hline & $\mathrm{R}^{\mathrm{w}}$ & 11.3 & 22.6 & 26.1 & 26.0 & 23.3 & 21.3 \\
\hline & $P^{\mathrm{x}}$ & $\ldots$ & 0.01 & $<0.01$ & $<0.01$ & $<0.01$ & 0.02 \\
\hline & Mean RG (sen) $)^{y}$ & 52.7 & 55.4 & 52.5 & 55.8 & 53.2 & 53.5 \\
\hline & $P^{\mathrm{z}}$ & $\ldots$ & 0.04 & 0.38 & 0.03 & 0.40 & 0.25 \\
\hline \multirow[t]{5}{*}{ Dodine } & $\mathrm{n}$ & 142 & 128 & 149 & 150 & 150 & 150 \\
\hline & $\mathrm{R}^{\mathrm{w}}$ & 9.9 & 17.2 & 19.5 & 10.7 & 26.7 & 16.7 \\
\hline & $P^{\mathrm{x}}$ & $\ldots$ & 0.05 & 0.01 & 0.67 & $<0.01$ & 0.05 \\
\hline & Mean RG $(\operatorname{sen})^{\mathrm{y}}$ & 55.0 & 55.7 & 55.0 & 52.8 & 59.7 & 55.8 \\
\hline & $P^{\mathrm{z}}$ & $\ldots$ & 0.71 & 0.98 & 0.60 & 0.01 & 0.63 \\
\hline
\end{tabular}

u Rates of fungicides (g a.i./1,000 liters) are given in parentheses.

${ }^{v}$ Isolates collected from nontreated trees.

${ }^{\mathrm{w}}$ Frequencies of isolates (\%) classified as resistant $(\mathrm{R})$ to fenarimol (relative growth [RG] $\left.>80\right)$ or dodine $(\mathrm{RG}>90)$.

$\mathrm{x}$ Comparison of counts of isolates classified as sensitive (S) or R obtained from nontreated trees with respective counts for isolates obtained from trees treated as specified (log linear model).

${ }^{y}$ Mean RG values of isolates sensitive to fenarimol $(\mathrm{RG} \leq 80)$ or dodine $(\mathrm{RG} \leq 90)$.

${ }^{\mathrm{z}}$ Comparison of mean RG values determined for the sensitive population of isolates retrieved from nontreated trees with respective means for isolates retrieved from trees treated as specified (Kolmogorov-Smirnov test).

Table 3. Control of Venturia inaequalis subpopulations sensitive (S) or resistant (R) to fenarimol or dodine

\begin{tabular}{|c|c|c|c|c|c|c|c|}
\hline \multirow[b]{3}{*}{ Treatment } & \multirow[b]{3}{*}{ Rate (mg a.i./liter) } & \multicolumn{6}{|c|}{ Mean control $(\%)^{\mathrm{v}}$} \\
\hline & & \multicolumn{3}{|c|}{ Fenarimol } & \multicolumn{3}{|c|}{ Dodine } \\
\hline & & $\mathbf{S}$ & $\mathbf{R}$ & $P^{w}$ & $\mathbf{S}$ & $\mathbf{R}$ & $P^{\mathbf{w}}$ \\
\hline Fenarimol & 15 & $59(14)^{x}$ & $14(24)$ & 0.05 & $57(16)$ & $20(27)$ & 0.13 \\
\hline Fenarimol & 30 & $83(4)$ & $54(14)$ & 0.10 & $82(5)$ & $60(10)$ & 0.02 \\
\hline Fenarimol & 15 & $\ldots$ & $\ldots$ & $\ldots$ & $\ldots$ & $\ldots$ & $\ldots$ \\
\hline + Mancozeb (mixture) $)^{\mathrm{y}}$ & 900 & $83(4)$ & $52(11)$ & 0.01 & $79(5)$ & $78(4)$ & 0.74 \\
\hline Fenarimol & 15 & $\ldots$ & $\ldots$ & $\ldots$ & $\ldots$ & $\ldots$ & $\ldots$ \\
\hline+ Mancozeb (fenarimol) $)^{z}$ & 900 & $64(4)$ & $17(8)$ & 0.01 & $62(4)$ & $27(9)$ & 0.004 \\
\hline Dodine & 290 & $82(12)$ & $56(30)$ & 0.23 & $83(12)$ & $39(38)$ & 0.14 \\
\hline Fenarimol & 15 & $\ldots$ & $\ldots$ & $\ldots$ & $\ldots$ & $\ldots$ & $\ldots$ \\
\hline + Dodine & 145 & 87 ( 7) & $72(5)$ & 0.02 & 86 ( 2) & $74(5)$ & 0.01 \\
\hline
\end{tabular}

$\mathrm{v}$ The levels of control (relative to the untreated check) achieved for sensitive and resistant subpopulations were calculated from disease incidences recorded for the various treatments in each year and averaged frequencies of sensitive or resistant isolates determined for isolates obtained from the respective treatments.

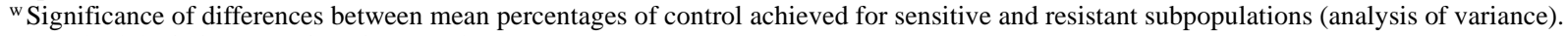

x Standard deviations are given in parentheses.

$y$ Calculated from the disease control and resistance frequency for trees treated with the mixture.

${ }^{z}$ Disease control was calculated by comparing incidences of scab on trees treated with the mixture relative to incidences on trees treated with mancozeb alone. Frequencies of sensitive and resistant isolates in the mancozeb-only treatment were assumed to be the same as for non-treated trees. 
was analyzed for all isolate sensitivities determined in 1993 and 1994. In these two seasons, sensitivities to myclobutanil were tested in addition to fenarimol in order to provide comparative data for a second DMI fungicide.

The fenarimol-sensitive subpopulation contained a significantly lower frequency of dodine-resistant isolates than the fenarimol-resistant subpopulation (Table 4). Although of slightly lower statistical significance, the same relationship applied to myclobutanil (Table 4). The result of this analysis indicated that resistance of $V$. inaequalis to DMIs and dodine was not an entirely independent trait, as would have been expected if double resistance arose from a random distribution of distinctly different resistance genes within a population. Applying the mixture of fenarimol and dodine could have been expected to accelerate the selection of double-resistant isolates. This expectation was not confirmed. The mean frequency of fenarimol-resistant isolates obtained from treatments with the mixture was $18.6 \%$ and that of dodine resistance was $12.7 \%$. If fenarimol and dodine resistance were independent traits, the expected frequency of double-resistant isolates would be $2.4 \%$. The frequency determined was $2.7 \%$ and, thus, not different from the expected frequency considering the sample size of 150 isolates tested.

Table 4. Relationship between resistance of Venturia inaequalis isolates to two sterol demethylation inhibitor (DMI) fungicides and to dodine

\begin{tabular}{lcccccc}
\hline & \multicolumn{3}{c}{ Fenarimol $^{\mathbf{x}}$} & & \multicolumn{3}{c}{ Myclobutanil } \\
\cline { 2 - 3 } \cline { 5 - 7 } & $\mathbf{S}$ & & $\mathbf{R}$ & & $\mathbf{S}$ & $\mathbf{R}$ \\
\hline Dodine $\mathrm{R}^{\mathrm{y}}$ & 16.3 & & 24.8 & & 16.6 & 23.5 \\
$\mathrm{n}$ & 472 & & 165 & & 477 & 162 \\
$P^{\mathrm{z}}$ & & 0.02 & & & & 0.06 \\
\hline
\end{tabular}

${ }^{\mathrm{x}} \mathrm{S}=$ sensitive, $\mathrm{R}=$ resistant.

${ }^{y}$ Frequency $(\%)$ of dodine-resistant isolates (relative growth $[R G]>90$ ) in populations either S or R $(\mathrm{RG}>80)$ to the DMIs fenarimol or myclobutanil.

${ }^{\mathrm{z}}$ Comparison of counts of dodine-resistant isolates classified as $\mathrm{S}$ or $\mathrm{R}$ to the DMIs fenarimol or myclobutanil (log-linear model).
In addition, the comparison of fenarimol and myclobutanil sensitivities (Table 4) confirmed the high degree of cross-resistance described before $(14,16)$. Although myclobutanil had not been applied in the orchard, frequencies of myclobutanil-resistant isolates were as high as fenarimol frequencies (Table 4).

Evaluation of DMI mixtures with mancozeb and dodine under commercial orchard conditions. Frequencies of resistance to fenarimol and myclobutanil for isolates retrieved from nontreated trees in six commercial orchards ranged from baseline to significantly higher than baseline (Table 5). However, all orchard populations were significantly $(P<0.01)$ less resistant than the threshold of practical resistance determined previously (16). For dodine, resistance was baseline at one of the orchards; at all other sites, resistance levels were significantly higher than baseline (Table 5). With the exception of orchard 4, all other levels of dodine resistance were also significantly $(P<0.01)$ lower than the threshold described for dodine (17; Table 5).

When a DMI was mixed with either mancozeb or dodine, scab control was equivalent or significantly higher with dodine as the mixing partner (Table 6). Scab control was not compromised at the two sites with elevated frequencies of iso- lates resistant to both fenarimol and dodine (orchards 5 and 6, Table 6). The different levels of control observed among orchards appeared to be more closely related to disease management practices rather than to respective levels of resistance at these sites. For example, the poor control of scab obtained in orchard 4 with myclobutanil employed as the DMI was associated with a $V$. inaequalis population whose frequency of myclobutanil-resistant isolates was not different from baseline (Table 5). Although the frequency of dodine-resistant isolates was relatively high in this orchard (Table 5), scab control was equally poor whether mancozeb or dodine was used as the mixing partner, providing further evidence that poor control of apple-scab development was due to inadequate management practices rather than fungicide resistance.

\section{DISCUSSION}

Strategies for delaying and managing fungicide resistance have two major goals: (i) slowing the rates at which resistant subpopulations are selected to sizes large enough to cause unacceptable levels of disease in the presence of respective fungicides, and (ii) preventing resistant subpopulations from compromising commercially acceptable disease control once resistant phenotypes have been selected to high frequencies. Both aspects were investigated in this study.

For fungicides characterized by a broad range of isolate sensitivities detected in baseline populations, as exemplified by both the DMIs (16) and dodine (17), the definition of isolates qualifying as resistant under practical conditions is central to efforts for monitoring resistance development and evaluating programs for its delay and management. Particular isolate sensitivities of $V$. inaequalis were defined resistant to DMIs or dodine, because such isolates had increased from low yet detectable baseline levels to high frequencies at sites with unsatisfactory control of apple

Table 5. Sensitivities to sterol demethylation inhibitor fungicides and dodine of Venturia inaequalis populations in six commercial New York apple orchards employed in 1996 trials

\begin{tabular}{|c|c|c|c|c|c|c|c|c|}
\hline \multirow[b]{2}{*}{ Fungicides } & \multirow[b]{2}{*}{ Baseline $^{x}$} & \multirow[b]{2}{*}{ Threshold $^{x}$} & \multicolumn{6}{|c|}{ Orchards } \\
\hline & & & 1 & 2 & 3 & 4 & 5 & 6 \\
\hline \multicolumn{9}{|l|}{ Fenarimol } \\
\hline $\mathrm{n}$ & 748 & 104 & 50 & 50 & 50 & 50 & 50 & 50 \\
\hline $\mathrm{R}^{\mathrm{y}}$ & 1.7 & 40 & 2 & 4 & 4 & 4 & 10 & 12 \\
\hline$P(\text { baseline })^{\mathrm{z}}$ & $\ldots$ & $\ldots$ & 0.89 & 0.32 & 0.32 & 0.32 & $<0.01$ & $<0.01$ \\
\hline \multicolumn{9}{|l|}{ Myclobutanil } \\
\hline $\mathrm{n}$ & 627 & 104 & 50 & 50 & 50 & 50 & 50 & 50 \\
\hline$R^{y}$ & 2.2 & 43 & 2 & 4 & 6 & 2 & 8 & 14 \\
\hline$P(\text { baseline })^{\mathrm{z}}$ & $\ldots$ & $\ldots$ & 0.91 & 0.47 & 0.16 & 0.91 & 0.04 & $<0.01$ \\
\hline \multicolumn{9}{|l|}{ Dodine } \\
\hline $\mathrm{n}$ & 232 & 174 & 50 & 50 & 50 & 50 & 50 & 50 \\
\hline $\mathrm{R}^{\mathrm{y}}$ & 0.9 & 41 & 4 & 10 & 8 & 48 & 12 & 10 \\
\hline$P(\text { baseline })^{\mathrm{z}}$ & $\ldots$ & $\ldots$ & 0.14 & $<0.01$ & 0.03 & $<0.01$ & $<0.01$ & $<0.01$ \\
\hline
\end{tabular}


scab $(16,17)$. It also had been shown that a DMI-resistant isolate was not insensitive to DMIs; rather, the isolate was still controlled at recommended application rates, although at a level which would be commercially unacceptable (16). These combined results suggested that control of the DMI-resistant subpopulation remains dependent on the DMI dose, with higher levels of control achieved at higher rates. Improved control of the resistant subpopulation can be expected to delay the selection of resistant populations to sizes at which control of scab becomes unacceptable under commercial conditions of apple production.

To separately determine under orchard conditions the level of control achieved for both the DMI-sensitive and -resistant subpopulations using various tactics of scab control was, therefore, the primary goal of the present study. Because a high degree of cross-resistance among several DMIs was established previously $(14,16)$ and confirmed in this study, fenarimol was chosen to represent the class. Although all treatments involving fenarimol increased the frequencies of DMI-resistant isolates of $V$. inaequalis, these increases had various impacts on the control of the DMI-resistant subpopulation. Control of resistant isolates was negligible for a low rate of fenarimol comparable to the minimum rate originally registered in the United States, whereas control of the fenarimol-resistant population was substantially improved at twice that rate.

As expected from the continuous distribution of isolate sensitivities established for the DMIs $(3,14,16,28)$, the low rate of fenarimol not only failed to control the DMI-resistant population, but it also selected isolates belonging to the least-sensitive segment of the population classified as DMI-sensitive under normal conditions of commercial scab control (16). This additional selection within the spectrum of sensitive isolates confirms that the definition of DMI resistance is not static but rather dependent on the rate at which a particular DMI is being used. At a higher rate of fenarimol, selection was restricted to the range of isolate sensitivities formerly defined as DMI-resistant (16); the lack of selection within the sensitive subpopulation indicates that sensitive isolates surviving treatment had merely escaped exposure to the fungicide. Thus, the differential and dose-dependent control of the DMI-resistant subpopulation suggests that the speed of selecting DMI-resistant isolates to large population sizes will be accelerated when DMIs are used at low rates and will be retarded when they are used at high rates.

The currently recommended and broadly accepted strategy for managing DMI resistance in apple scab control is to employ DMIs mixed with a protective fungicide (25). Because financial concerns often cause commercial apple growers to minimize rates of the individual components in fungicide mixtures, we chose to use fenarimol at the minimal rate and the EBDC mancozeb at the rate traditionally employed and recently mandated for use in fungicide mixtures applied to apples in the United States. Although control of the DMI-resistant subpopulation with this mixture was equivalent to the control provided by twice the rate of fenarimol applied singly, our data clearly indicate that control of resistant isolates was provided almost exclusively by the mancozeb component of the mixture. The observation that isolates belonging to the least-sensitive spectrum of the DMI-sensitive subpopulation were selected by the minimal rate of fenarimol whether or not mancozeb was present confirmed that the protective component in mixture with fenarimol acted in a merely additive fashion.

The results illustrate the importance of recognizing the spatial separation of mancozeb and fenarimol action. Mancozeb inhibits spore germination on protected surfaces without providing any postinfection activity (30). In contrast, DMIs in general are poor germination inhibitors (10) and halt infections by $V$. inaequalis most effectively after the pathogen has penetrated the host surface and becomes established within the apple tissue $(22,26,30)$. Our data document that a protective fungicide such as mancozeb applied in mixture with DMIs at a low rate will have no impact on the speed of selecting DMI-resistant isolates; the speed will be determined only on the basis of the DMI rate they encounter. As the frequency of DMI-resistant isolates increases over time, control will become increasingly reliant on the protective component of the mixture, and the mixture will become progressively less effective when applied in the after-infection mode favored originally by the DMIs.

In contrast to the low rate of fenarimol applied singly or in mixture with mancozeb, fenarimol applied at twice that rate provided improved control of the fenarimol-resistant subpopulation. Thus, our results imply that the two different principles of managing DMI resistant subpopulations-indiscriminate control provided by a protective mixing partner and superior control provided by a high DMI rate-must be combined to complement each other. However, it is important to recognize that the contribution of the protective partner will increase in importance as the DMIresistant subpopulations of $V$. inaequalis increase in relative sizes. As this occurs, spray timings will need to be adjusted in order to ensure that effective concentrations of the protectant are present at the beginning of apple scab infection periods.

The implications of using dodine as an alternative mixing partner in DMI antiresistance strategies are different from those discussed above for mixtures of DMIs with protective fungicides. In contrast to fungicides active exclusively in a protective mode, dodine can also be active against the formation of conidia after infections have occurred $(1,30)$. Also in contrast to purely protective fungicides, severe cases of resistance have been documented for dodine $(7,8,17,20,27,32)$. Therefore, the selection of isolates doubleresistant to both DMIs and dodine is of concern when DMIs and dodine are applied in mixture. Indeed, fenarimol applied singly increased the frequency of dodine-resistant isolates, and dodine applied singly increased frequencies of fenarimol-resistant isolates. Furthermore we found a higher frequency of

Table 6. Control of scab in six New York apple orchards using a sterol demethylation inhibitor (DMI) mixed with an ethylenebisdithiocarbamate (EBDC) or with dodine

\begin{tabular}{|c|c|c|c|c|c|c|c|}
\hline \multirow[b]{2}{*}{ Tissue } & \multirow[b]{2}{*}{ Mixture component } & \multicolumn{6}{|c|}{ Mean disease incidence in each orchard } \\
\hline & & $\mathbf{1}^{\mathrm{w}}$ & $2^{w}$ & $3^{x}$ & $4^{x}$ & $5^{w}$ & $6^{x}$ \\
\hline \multirow[t]{2}{*}{ Cluster leaves } & $\mathrm{EBDC}^{\mathrm{y}}$ & 0.42 & $<0.4$ & 14.4 & 89.2 & $<0.4$ & 5.6 \\
\hline & Dodine & 2.8 & $<0.4$ & 10.4 & 98.4 & $<0.4$ & 1.2 \\
\hline$P^{\mathrm{z}}$ & $\ldots$ & 0.8 & $\ldots$ & 0.3 & 0.3 & $\ldots$ & 0.1 \\
\hline \multirow[t]{2}{*}{ Terminal leaves } & $\mathrm{EBDC}^{\mathrm{y}}$ & 0.4 & $<0.1$ & 9.9 & 27.0 & $<0.1$ & 4.8 \\
\hline & Dodine & 1.7 & $<0.1$ & 6.4 & 31.2 & $<0.1$ & 1.6 \\
\hline$P^{\mathrm{z}}$ & $\ldots$ & 0.07 & $\ldots$ & 0.04 & 0.3 & $\ldots$ & $<0.01$ \\
\hline \multirow{2}{*}{ Fruit } & $\mathrm{EBDC}^{\mathrm{y}}$ & $<0.2$ & $<0.2$ & 10.4 & 60.8 & $<0.2$ & 1.0 \\
\hline & Dodine & 0.4 & $<0.2$ & 1.8 & 57.6 & $<0.2$ & 0.8 \\
\hline$P^{\mathrm{z}}$ & $\ldots$ & 0.2 & $\ldots$ & $<0.01$ & 0.6 & $\ldots$ & $<0.01$ \\
\hline
\end{tabular}

wDMI used was fenarimol (Rubigan 1EC).

${ }^{x}$ DMI used was myclobutanil (Nova 40W).

y Metiram (Polyram 80WP) in orchard 2 and mancozeb (Dithane 75DF) in all other orchards.

${ }^{\mathrm{z}}$ Comparison of means of scab incidences between the two mixtures (analysis of variance). 
dodine-resistant isolates in the fenarimolresistant subpopulation than in the fenarimol-sensitive population.

The latter result indicates that resistance to dodine and DMIs is not an entirely independent trait, regardless of the different modes of action of the two fungicides (4). Although not understood at present, the phenomenon might relate to the genetics and, thus, mechanisms of resistance to either dodine or the DMIs. Resistance of $V$. inaequalis to dodine has been described as multi-genic $(23,32)$. DMI resistance of $V$. inaequalis genotypes representing a relatively narrow range of sensitivities was previously related to a single gene (29); however, genetic analysis of isolates representing the entire spectrum of isolate sensitivities indicated a multigenic trait (G. Olaya and W. Köller, unpublished). One of the multiple mechanisms conferring resistance to dodine or DMIs might affect both fungicides, (e.g., by relating to the phenomenon of pleiotropic resistance mediated by membrane transport systems, which is known to lower the intracellular concentrations of unrelated inhibitors; 5,6). The potential relationship between DMI and dodine resistance in $V$. inaequalis populations not withstanding, the low-rate mixture of fenarimol and dodine evaluated in this study did not detectably increase the speed of selecting double-resistant isolates. Moreover, control of the fenarimol- and dodine-resistant subpopulations provided by the mixture was superior to and more consistent than that provided by either component applied singly at twice the mixture rate.

The good performance of a DMI mixed with dodine in the experimental orchard was confirmed in commercial orchard trials. Here, the performances of DMIdodine mixtures were equivalent or superior to DMIs mixed with an EBDC, even when resistance levels of one or both fungicides were higher than baseline. It must be emphasized, however, that a mixture of DMIs with dodine can be expected to fail in orchards when the frequencies of both DMI- and dodine-resistant isolates are approaching threshold values $(16,17)$, because the relatively high level of doubleresistant isolates can be expected to be controlled poorly by both components present in the mixture.

Our strategy of evaluating the relative merits of anti-resistance strategies was based on (i) developing and testing quantitative monitoring procedures $(14,16,17,28)$; (ii) defining isolate sensitivities qualifying as sensitive or resistant $(16,17)$; (iii) quantifying the baseline and threshold sensitivities of resistant $V$. inaequalis populations $(14,16,17,28)$; and (iv) applying these techniques and respective monitoring data in determining the differential control of sensitive and resistant subpopulations under different regimes of scab control. This sequence of exploratory events should be applicable to other host-pathogen systems and to other fungicides, particularly if resistant isolates are part of a continuous and broad distribution of isolate sensitivities already detectable in baseline populations $(16,17)$. As described recently, isolate sensitivities in baseline populations of $V$. inaequalis also are distributed broadly for kresoxim-methyl (21), a member of the new class of strobilurin fungicides (33). It remains to be investigated whether the highrate strategy recommended for the DMI fungicides will also be of merit in delaying strobilurin resistance.

\section{ACKNOWLEDGMENTS}

We thank D. Breth, J. A. Burr, J. R. Nevill, and C. A. Smith for their assistance; and Dow Agrosciences and United Agri Products for financial aid and for providing commercial fungicides.

\section{LITERATURE CITED}

1. Albert, J. J., and Lewis, F. H. 1962. Effect of repeated applications of dodine and of captan on apple scab foliage lesions. Plant Dis. Rep. 46:163-167.

2. Braun, P. G. 1994. Development and decline of a population of Venturia inaequalis resistant to sterol-inhibiting fungicides. Norw. J. Agric. Sci. 17 (Suppl.):173-184.

3. Braun, P. G., and McRae, K. B. 1992. Composition of a population of Venturia inaequalis resistant to myclobutanil. Can. J. Plant Pathol. 14:215-220.

4. Buchenauer, H. 1990. Physiological reactions in the inhibition of plant pathogenic fungi. Pages 217-392 in: Chemistry of Plant Protection, Vol. 6. G. Haug and H. Hoffmann, eds. Springer-Verlag, Berlin.

5. De Waard, M. A. 1997. Significance of ABC transporters in fungicide sensitivity and resistance. Pestic. Sci. 51:271-275.

6. De Waard, M. A., van Nistelrooy, J. G. M., Langveld, C. R., Van Kan, J. A. L., and Del Sorbo, G. 1996. Multidrug resistance in filamentous fungi. Pages 293-300 in: Modern Fungicides and Antifungal Compounds. $\mathrm{H}$. Lyr, P. E. Russell, and H. D. Sisler, eds. Intercept, Andover, UK.

7. Gilpatrick, J. D. 1982. Case study 2: Venturia on pome fruits and Monilinia on stone fruits. Pages 195-206 in: Fungicide Resistance in Crop Protection. J. Dekker and S. G. Georgopoulos, eds. Centre for Agricultural Publishing and Documentation, Wageningen, Netherlands.

8. Jones, A. L., and Walker, R. J. 1976. Tolerance of Venturia inaequalis to dodine and benzimidazole fungicides in Michigan. Plant Dis. Rep. 60:40-42.

9. Köller, W. 1991. Fungicide resistance in plant pathogens. Pages 679-720 in: CRC Handbook of Pest Management in Agricultue, 2nd Ed., Vol. 2. D. Pimentel, ed. CRC-Press, Boca Raton, FL.

10. Köller, W. 1992. Antifungal agents with target sites in sterol functions and biosynthesis. Pages 119-206 in: Target Sites of Fungicide Action. W. Köller, ed. CRC Press, Boca Raton, FL.

11. Köller, W. 1994. Chemical control of apple scab-status quo and future. Norw. J. Agric. Sci. Suppl. 17:149-170

12. Köller, W. 1995. Managing resistance to sterol demethylation inhibitors. Pages 340349 in: Eighth International Congress of Pesticide Chemistry-Options 2000. N. N. Ragsdale, P. C. Kearny, and J. R. Plimmer, eds., American Chemical Society, Washington, DC.

13. Köller, W. 1996. Recent developments in DMI resistance. Pages 301-311 in: Modern Antifungal Compounds. H. Lyr, P. E. Russel, and H. D. Sisler, eds., Intercept Ltd., Andover, UK.

14. Köller, W., Parker, D. M., and Reynolds, K. L. 1991. Baseline sensitivities of Venturia inae qualis to sterol demethylation inhibitors. Plant Dis. 75:726-728.

15. Köller, W., and Scheinpflug, H. 1987. Fungal resistance to sterol biosynthesis inhibitors: A new challenge. Plant Dis. 71:1066-1074.

16. Köller, W., Wilcox, W. F., Barnard, J., Jones, A. L., and Braun, P. G. 1997. Detection and quantification of resistance of Venturia inaequalis populations to sterol demethylation inhibitors. Phytopathology 87:184-190.

17. Köller, W., Wilcox, W. F., and Jones, A. L. 1999. Quantification, persistence and status of dodine resistance in New York and Michigan orchard populations of Venturia inaequalis. Plant Dis. 83:66-70.

18. Kuck, K. H., Scheinpflug, H., and Pontzen, R 1995. DMI fungicides. Pages 205-258 in Modern Selective Fungicides, 2nd Ed. H. Lyr, ed. Gustav Fischer Verlag, Jena, Germany.

19. Kunz, S., Deising, H., and Mendgen, K. 1997. Acquisition of resistance to sterol demethylation inhibitors by populations of Venturia inaequalis. Phytopathology 87:1272-1278.

20. McKay, M. C. R., and MacNeill, B. H. 1979 Spectrum of sensitivity to dodine in field populations of $V$. inaequalis. Can. J. Plant Pathol. 1:76-78.

21. Olaya, G., and Köller, W. 1999. Baseline sensitivities of Venturia inaequalis populations to the strobilurin fungicide kresoximmethyl. Plant Dis. 83:274-278.

22. O'Leary, A. L., Jones, A. L., and Ehret, G. R. 1987. Application rates and spray intervals for apple scab control with flusilazol and pyrifenox. Plant Dis. 71:623-626.

23. Polach, F. J. 1973. Genetic control of dodine tolerance in Venturia inaequalis. Phytopathology 63:1189-1190.

24. Richter, D. L. 1987. Synergism-a patent point of view. Pestic. Sci. 19:309-315.

25. Scheinpflug, H. 1988. Resistance management strategies for using DMI fungicides. Pages 93-94 in: Fungicide Resistance in North America. C. J. Delp, ed. APS Press, St. Paul, MN.

26. Schwabe, W. F. S., Jones, A. L., and Jonker, J P. 1984. Greenhouse evaluation of the curative and protective action of sterol-inhibiting fungicides against apple scab. Phytopathology 74:249-252.

27. Sholberg, P. L., Yorston, J. M., and Warnock, D. 1989. Resistance of Venturia inaequalis to benomyl and dodine in British Columbia, Canada. Plant Dis. 73:667-669.

28. Smith, F. D., Parker, D. M., and Köller, W. 1991. Sensitivity distribution of Venturia inaequalis to flusilazole: baseline sensitivity and implications for resistance monitoring. Phytopathology 81:392-396.

29. Stanis, V. F., and Jones, A. L. 1985. Reduced sensitivity to sterol inhibiting fungicide in field isolates of Venturia inaequalis. Phytopathology 75:1098-1101.

30. Szkolnik, M. 1981. Physical modes of action of sterol-inhibiting fungicides against apple diseases. Plant Dis. 65:981-985.

31. Wilcox, W. F., Wasson, D. I., and Kovach, J. 1992. Development and evaluation of an integrated, reduced-spray program using sterol demethylation inhibitor fungicides for control of primary apple scab. Plant. Dis. 76:669-677.

32. Yoder, K. S., and Klos, E. J. 1976. Tolerance to dodine in Venturia inaequalis. Phytopathology 66:918-923.

33. Ypema, H. L., and Gold, R. E. 1999 Kresoxim-methyl. Modification of a naturally occurring compound to produce a new fungicide. Plant Dis. 83:4-19. 